\title{
Effect of Interferential Therapy on Chronic Pain After Inguinal Hernioplasty
}

\author{
Heba M. Mohamady ${ }^{1}$, Asmaa A. Saber ${ }^{2, ~ *, ~ A l y ~ S a b e r ~}{ }^{2}$ \\ ${ }^{1}$ Lecturer of Physical Therapy Department for Surgery, Faculty of Physical Therapy, Cairo, Cairo University, Egypt \\ ${ }^{2}$ Port-Fouad general Hospital, Port-Fouad, Egypt
}

Email address:

Soma1_25_2008@yahoo.com (A. A. Saber)

\section{To cite this article:}

Heba M. Mohamady, Asmaa A. Saber, Aly Saber. Effect of Interferential Therapy on Chronic Pain After Inguinal Hernioplasty. Journal of Surgery. Special Issue: Postoperative Pain Syndrome. Vol. 3, No. 2-1, 2015, pp. 14-17. doi: 10.11648/j.js.s.2015030201.13

\begin{abstract}
Introduction: Chronic postoperative pain is strongly related to patient-related factors surgery- related factors. Treatment of chronic groin pain after surgery may be difficult for both the patient and the surgeon and many algorithms have been advocated but none of them has been accepted totally. Interferential Therapy has been used in clinical practice for reducing pain and other symptoms following musculoskeletal injury. This current study was designed to detect the therapeutic efficacy of Interferential Therapy as a method of treatment to reduce chronic post operative pain after inguinal hernia repair. Subjects and Methods: A total of 40 adult male patients were operated upon as inguinal hernioplasty with synthetic mesh repair and their ages were ranged from 30-50 years. Patients were randomly assigned into two equal groups; Group A (Interferential Therapy group) and Group B (Control group). Patients of group A underwent inguinal hernioplasty with synthetic mesh and received the application of interferential therapy over the operative skin incisions in addition they received the routine postoperative analgesia. Regarding the postoperative pain, the assessment approaches were subdivided into 3 main procedures: Visual Analog Scale, prosthesis awareness and physical activity. Results: Total pain score was the sum VAS, prosthesis awareness and physical activity scores. We observed that statistical analysis of total pain scores and the final scores per patient in both groups of this study were statistically significant. Conclusion: Interferential current as a supplement to traditional analgesia in the early postoperative course in hernia repair with mesh seems to be more effective for reducing pain than traditional postoperative analgesia alone. Interferential current therapy is a noninvasive therapy for relief from chronic postsurgical pain. It provides a safe, with minimal side effects and effective alternative to pharmacological approaches to pain control.
\end{abstract}

Keywords: Inguinal Hernioplasty, Interferential Therapy, Chronic Pain

\section{Introduction}

The surgical methods of inguinal hernia repair can be divided into tension repairs as Bassini's technique with numerous modifications and tension-free with the use of synthetic meshes [1]. Chronic postoperative pain is defined as pain lasting more than three months after surgery and in general is strongly related to two main patient-related factors; age and body mass index or three surgery- related factors such as surgery for recurrence with anterior approach, operations performed in specialist hernia centers and finally the experience of the surgeon [2]. The treatment of chronic groin pain after surgery may be difficult for both the patient and the surgeon and many algorithms have been advocated but none of them has been accepted totally. Life style modification and administration of pharmacological agents are usually used [3]. The role of physical therapy in the management of chronic groin pain was studied. Massage, physiotherapy and acupuncture have been tried [3]. Thermotherapy was used to temporarily alleviate the painful stimulus and Capsaicin cream was applied topically as a counter-irritant to desensitize painful stimulus [4] and [5]. Interferential Therapy (IFT) has been used in clinical practice for reducing pain and other symptoms following musculoskeletal injury. In fact, there is still controversy surrounding the depth efficiency and whether voltages can be induced in deep tissues by IFC [6].

This current study was designed to detect the therapeutic efficacy of Interferential Therapy as a method of treatment to reduce chronic post operative pain after inguinal hernia repair. 


\section{Subjects, Materials and Methods}

A total of 40 adult male patients were operated upon as inguinal hernioplasty with synthetic mesh repair and their ages were ranged from 30-50 years. These patients were selected from the outpatient clinic of Port-Fouad General Hospital, Port-Fouad, Egypt .The diagnosis was performed clinically by the consultant surgeon.

Patients were randomly assigned into two equal groups; Group A (Interferential Therapy group) and Group B (Control group). Patients of group A underwent inguinal hernioplasty with synthetic mesh and received the application of interferential therapy over the operative skin incisions in addition they received the routine postoperative analgesia. The electrical current was applied to the affected area using four electrodes. The four electrodes were placed in such a way that the two currents produced cross each other in the affected area. The electrodes were usually used with a damp sponge placed between the electrode and the patient's skin or a conductive gel may be used. The intensity of the current was increased within the patient's comfort level [7].

Group B patients underwent inguinal hernioplasty with mesh repair but received placebo interferential and in addition they received the routine postoperative analgesia.

Patients with co-morbidity such as cardiac, renal or hepatic diseases, those with uncontrolled diabetes, having strangulated hernia at presentation or with postoperative wound sepsis also were excluded from the study.

Written consents were obtained from all patients before the study. The steps of both treatment policies was explained to all patients by the treating team and the ethical review committee under supervision of the general director of PortFouad general hospital, Port-Fouad, Port-Said, Egypt.

Regarding the postoperative pain, the assessment approaches were subdivided into 3 main procedures: Visual Analog Scale, prosthesis awareness and physical activity

1- Visual Analogue Scale (VAS) is a measurement instrument that tries to measure a characteristic or attitude that is believed to range across a continuum of values and cannot easily be directly measured. For example, the amount of pain that a patient feels ranges across a continuum from none to an extreme amount of pain [8]:

Mild $(1-4)=1$ point,

Moderate $(5-7)=2$ points,

Severe $(8-10)=3$ points

\subsection{Prosthesis Awareness}

A questionnaire was signed by the patient about his feeling of the presence of the mesh in the operative field and the score was as following: [2].

Yes $=1$ point,

$\mathrm{No}=0$ point.

\subsection{Physical Activity}

It was stated that the chronic post hernioplasty pain actually has impact on the patient's everyday life and activities such as restrictions during work, sport, or other leisure activities: [9]

Pain only on exertion $=1$

Pain limits some daily activity $=2$,

Disabling pain $=3$.

\subsection{Statistical Analysis}

Data were entered and analyzed using SPSS (Statistical Package for Social Sciences) software program version 15.0 for analysis. Student t test was used to compare categorical variables. $\mathrm{P}$ value set at $<0.05$ for significant results.

\section{Results}

We studied our patients according to their jobs, their education status, and their ordinary daily efforts and according to their special habits such as smoking, athletics and drug addiction. There was no significant difference between the two groups regarding the sociodemographic data and special habits $[P \geq 0.05]$.

The mean differences of pain score (VAS) in the pretreatment course of the (IFT) group (group A) was 4.35 \pm 1.49 , with maximum and minimum values of 9 and 3 respectively, while the mean value after one month of treatment application (post-treatment) was $.9 \pm 1.2$ with maximum and minimum values of 5 and 0 respectively $\{P=0.0001\}$. However, the mean value of pain score (VAS) in the pretreatment course of control group (group B) was $6 \pm 1.55$, with maximum and minimum values of 10 and 3 respectively, while the mean post-treatment value was $4.35 \pm 2.13$ with maximum and minimum values of 8 and 1 respectively $\{P=$ $0.9\}$.

We observed that there was no significant difference in the mean values of pain (VAS) score (pre-treatment application) between both groups while a statistical significant difference in the mean values of pain (VAS) score post-treatment application was evident $\{P=0.0001\}$.[Table 1]

Table 1. Comparison between post-treatment in both groups of the study (A and $B$ )

\begin{tabular}{lll}
\hline \multirow{2}{*}{ Statistical Analysis } & VAS & \\
\cline { 2 - 3 } & $\begin{array}{l}\text { Post-treatment } \\
\text { (group A) }\end{array}$ & $\begin{array}{l}\text { Post-treatment } \\
\text { (group B) }\end{array}$ \\
\hline Mean (X) & 0.9 & 4.35 \\
Standard Deviation (SD) & 1.2 & 2.13 \\
Maximum & 5 & 8 \\
Minimum & 0 & 1 \\
P value & 0.0001 & \\
Level of Significance & Significant & \\
\hline
\end{tabular}

The mean value of pain during physical activity before treatment application in group A was $.2 \pm 0.05$, with maximum and minimum values of 2 and 0 respectively, while the mean value of physical activity after one month of treatment application (post-treatment) was $.05 \pm 0.22$ with maximum and minimum values of 1 and 0 respectively $\{P=0.005\}$. While in group B the pretreatment and post treatment values were $0.5 \pm 1$, with maximum and minimum values of 3 and 0 
respectively $0.3 \pm 0.8$ with maximum and minimum values of 3 and 0 respectively $\{\mathrm{P}=0.69\}$.

Table 2 showed that there was a non significant difference in the mean values of physical activity (post-treatment) between both groups while despite being higher in group A, also nonsignificant distribution was observed in the posttreatment mean values of physical activity of both groups.

Table 2. Comparison between post-treatment in both groups of the study (A and $B$ )

\begin{tabular}{|c|c|c|}
\hline \multirow[b]{2}{*}{ Statistical Analysis } & \multicolumn{2}{|l|}{ Physical Activity } \\
\hline & $\begin{array}{l}\text { Post-treatment } \\
\text { (group A) }\end{array}$ & $\begin{array}{l}\text { Post-treatment } \\
\text { (group B) }\end{array}$ \\
\hline $\mathrm{X}$ & 0.05 & 0.3 \\
\hline $\mathrm{SD} \pm$ & 0.22 & 0.8 \\
\hline Maximum & 1 & 3 \\
\hline Minimum & 0 & 0 \\
\hline$P$ value & 0.18 & \\
\hline Level of Significance & Non-significant & \\
\hline
\end{tabular}

We observed that in the treatment group $A$, the two patients were aware of the presence of prosthesis having pain on exertion and in the control group; among the three patients who were aware of the presence of prosthesis two experienced pain that limited the daily activity and disabling pain while the third one experienced pain on exertion.

Table 3. Number of patient's physical activities and prosthetic awareness with the T and $P$ values.

\begin{tabular}{llllll}
\hline Group & N & $\%$ & $\begin{array}{l}\text { Prosthetic } \\
\text { Awareness }\end{array}$ & $\begin{array}{l}\text { Physical } \\
\text { activities }\end{array}$ & P Value \\
\hline A & 2 & 10 & 1 & 1 & $0.03(\mathrm{~S})$ \\
B & 6 & 30 & 3 & 3 & \\
\hline
\end{tabular}

N: Number; S: Significant

Total pain score was the sum VAS, prosthesis awareness and physical activity scores. In patients of group A, VAS score was three points while prosthesis awareness took three points and the patients' physical activity had also one point with a total score of five points. In the other hand in patients of group B, VAS score was eleven points while prosthesis awareness took one point and the patients' physical activity had six points with a total score of twenty points.

Table 4. Detailed descriptions as regard VAS, prosthesis awareness and physical activity of total pain in both groups.

\begin{tabular}{|c|c|c|c|c|c|}
\hline \multirow{2}{*}{ Group } & \multirow{2}{*}{\multicolumn{2}{|c|}{$\begin{array}{l}\text { VAS } \\
\mathbf{N}\end{array}$}} & \multirow{2}{*}{$\begin{array}{l}\text { Prosthesis awareness } \\
\mathbf{N}\end{array}$} & \multirow{2}{*}{$\begin{array}{l}\text { Physical Activity } \\
\text { N }\end{array}$} & \multirow{2}{*}{ P value } \\
\hline & & & & & \\
\hline A $N=2$ & $\begin{array}{ll}\text { Mild } 1 \\
\text { Mod } 1\end{array}$ & Severe 0 & $\begin{array}{l}\text { Yes } 1 \\
\text { No } 0\end{array}$ & $\begin{array}{l}\text { Pain on exertion } 1 \\
\text { Pain limits activity } 0 \\
\text { Disabling pain } 0\end{array}$ & \multirow[b]{2}{*}{$0.033(\mathrm{~S})$} \\
\hline B $N=6$ & $\begin{array}{ll}\text { Mild } & 2 \\
\text { Mod } & 3\end{array}$ & Severe 1 & $\begin{array}{ll}\text { Yes } & 3 \\
\text { No } & 0\end{array}$ & $\begin{array}{l}\text { Pain on exertion } 1 \\
\text { Pain limits activity } 1 \\
\text { Disabling pain } 1\end{array}$ & \\
\hline
\end{tabular}

N: Number; S: Significant

In patients of group $\mathrm{A}$, the sum of VAS, prosthesis awareness and the patients' physical activity scores was five points and pain score per patient was calculated as 2.5.

Accordingly, in group B the sum of VAS, prosthesis awareness and the patients' physical activity scores was twenty points and pain score per patient was calculated as 3.2. On revising table [5], we observed that statistical analysis of total pain scores and the final scores per patient in both groups of this study were statistically significant.

Table 5. Total pain score as well as the final pain score per patient.

\begin{tabular}{llllll}
\hline Group & Total pain score & Pain score per patient & T value & P value & Significance \\
\hline A & 5 & 2.5 & \multirow{2}{*}{1.86} & 0.049 \\
B & 20 & 3.2 & The result is significant & \\
\hline
\end{tabular}

\section{Discussion}

In this prospective study, forty adult male patients were operated upon for inguinal hernioplasty with synthetic mesh repair and their ages were ranged from 30-50 years. There was no statistical significant difference between the two groups as regard age, special habits and the socioeconomic background $[P \geq 0.05]$. This distribution came in agreement with other studies of same interest [2].

Chronic postoperative pain is strongly related to two main factors; patient-related factors and surgery- related factors. The patient-related factors are age and body mass index and the surgery- related factors such as type of repair, operations performed in specialist hernia centers and finally the experience of the surgeon [2].
Chronic postoperative pain was observed in $2 / 20$ patients in group A $(10 \%)$ and in $6 / 20$ patients in group B $(30 \%)$. Many similar studies reported that the incidence of chronic pain after hernioplasty with mesh was $10-30 \%$ [2] and [10], and might reach up to $40 \%$ [3] while a number of studies reported incidence rates of chronic pain varying from $0 \%$ to $37 \%$ with the overall incidence was reported to be $12 \%$ [11]. Other stated the frequency of chronic pain after inguinal hernia repair to be as high as $54 \%$ [12]. To explain this discrepancy, we found that the observational methods for pain evaluation vary, prospective studies are few and chronic pain is not a primary outcome parameter in most studies [11] and [13].

Recently, it was found an increased incidence of chronic pain in patients who had a mesh repair compared with those 
who had a suture repair [14]. Indeed Hakeem and his colleagues reported that mesh-related fibrosis is a major contribution to the chronic groin pain after mesh hernioplasty [3]. The evidence based effective treatment of post-operative chronic groin pain is unclear. Surgical exploration with division of all three nerves with, or without, the removal of the mesh is associated with mixed results [15]. In their series, Aroori and Spence achieved a $75 \%$ success rate using a combination of nerve blocks and anti-neuropathic medication using methyl prednisolone acetate as a synthetic corticosteroid providing long-term pain relief when injected into localised areas of chronic and acute inflammation [14].

The physiological effects of IFC show increase in localized blood flow which can improve healing by reducing swelling and help removing damaged tissue and bringing nutrients to the injured area. IFC causes blocking the transmission of the pain signals and stimulating the release of pain reducing endorphins [7].

The most common use of IFC is to relieve pain, although some therapists also report using IFC for the reduction of swelling, the healing of wounds and fractures, and the restoration of function associated with muscle weakness [16]. The purpose of IFC therapy is to deliver currents to deepseated tissue. Currents with a kilohertz cycle duration are used in an effort to overcome skin impedance and penetrate deep into the body. Some authors claim that the amplitudemodulated interference wave is what makes IFC potentially effective and that by delivering it at frequencies between 1 and $250 \mathrm{~Hz}$, IFC will elicit a physiological response that leads to pain relief [7].

The physiological effects of IFC include vasodilating effects that helping venous return, lymphatic drainage, also, allows the rapid elimination of toxic metabolic products, ensures better oxygen supply to the tissue, in addition it changes $\mathrm{pH}$ to the alkaline side and helps to disperse infiltration and adhesions [17].

\section{Conclusion}

Use of interferential current is a common electrotherapeutic modality to treat pain. Interferential current as a supplement to traditional analgesia in the early postoperative course in hernia repair with mesh seems to be more effective for reducing pain than traditional postoperative analgesia alone. Interferential current therapy is a noninvasive therapy for relief from chronic post-surgical pain. It provides a safe, with minimal side effects and effective alternative to pharmacological approaches to pain control.

\section{References}

[1] Simons M, Aufenacker T, Bay-Nielsen M, Bouillot J, Campanelli G, Conze J. European Hernia Society guidelines on the treatment of inguinal hernia in adult patients. Hernia, 2009,13(4):343-403.
[2] Saber A, Ellabban G, Gad M, Elsayem K. Open preperitoneal versus anterior approach for recurrent inguinal hernia: a randomized study. BMC Surg, 2012, 30: 12:22.

[3] Hakeem A, Shanmugam V.: "Inguinodynia following Lichtenstein tension-free hernia repair:" a review. World journal of gastroenterology,2011, 17(14):1791-6.

[4] Keller JE, Stefanidis D, Dolce CJ, Iannitti DA, Kercher KW, Heniford BT. "Combined open and laparoscopic approach to chronic pain after inguinal hernia repair.” Am Surg 2008; 74: 695-700.

[5] Ferzli GS, Edwards ED, Khoury GE. "Chronic pain after inguinal herniorrhaphy.” J Am Coll Surg 2007; 205: 333-341.

[6] Beatti A, Rayner A, Chipchase L, Souvlis T. Penetration and spread of interferential current in cutaneous, subcutaneous and muscle tissues. Physiotherapy,2011, 97:319-326.

[7] Jorge S, Parada C, Ferreira S, Tambeli C. Interferential therapy produces antinociception during application in various models of inflammatory pain. Phys. Ther,2006, 86(6): 800808 .

[8] Jensen MP, Chen C, Brugger AM. Interpretation of visual analog scale ratings and change scores: a reanalysis of two clinical trials of postoperative pain. J Pain. 2003 ;4(7):407-14.

[9] Aasvang E., Møhl B. and Kehlet H. (2007): "Ejaculatory pain: a specific postherniotomy pain syndrome?" Anesthesiology; 107:298-304.

[10] Schouten N, Van Dalen T, Smakman N, Elias S, Clevers G, Verleisdonk E, Davids P, Burgmans I. The effect of ultrapro or prolene mesh on postoperative pain and well-being following endoscopic Totally Extraperitoneal (TEP) hernia repair (TULP). study protocol for a randomized controlled trial. Trials,2012, Jun 7;13:76.

[11] Erhan Y, Erhan E, Aydede H, Mercan M, Tok D.Chronic pain after Lichtenstein and preperitoneal (posterior) hernia repair. Can J Surg,2008,October; 51(5): 383-387.

[12] Poobalan A, Bruce J, Smith W, King P, Krukowski Z, Chambers W. A review of chronic pain after inguinal herniorrhaphy. Clin J Pain ,2003,19(1):48-54.

[13] Koninger J, Redecke J, Butters M. Chronic pain after hernia repair: a randomized trial comparing Shouldice, Lichtenstein and TAPP. Langenbecks Arch Surg,2004, 389:361-5.

[14] Aroori S, Spence R.Chronic pain after hernia surgery -An Informed Consent Issue. Ulster Med J,2007, 76(3): 136-140.

[15] Amid P. Causes, prevention, and surgical treatment of postherniorrhaphy neuropathic inguinodynia: triple neurectomy with proximal end implantation. Hernia,2004, $8(4): 343-9$.

[16] Johnson M, Tabasam G. An investigation into the analgesic effects of interferential currents and transcutaneous electrical nerve stimulation on experimentally induced ischemic pain in otherwise pain-free volunteers. Phys. Ther.2003,83(3):208-23.

[17] Hanfy H, Thabet A, Saleh A, Shahin M. Efficacy of Low Level Laser Versus Interferential in the Treatment of Chronic Pelvic Inflammatory Disease. Bull. Fac. Ph. Th. Cairo Univ,2009, 14( 2): 105-116. 